\title{
P-52
}

\section{The Phytochemistry Of Syzygium Species}

\author{
Mohd Fathi Abdul Wahab, Mohamad Fariz Hashim, Mohd Hafiz Yusof, Hannis Fadzillah Mohsin* \\ and Ibtisam Abdul Wahab
}

Faculty of Pharmacy, Universiti Teknologi MARA, $42300 \quad$ Puncak Alam, Malaysia;

E-mail: hannis@puncakalam.uitm.edu.my

This review deals with the literatures on Syzygium species (family: Myrtaceae). It was mentioned as a source of traditional medicine to treat diabetes mellitus. However, due to the lacking information on Syzygium cumini, its potential benefit is still unknown among the local. This plant, commonly known as black plum, is a plant native to India. Studies from abroad showed that $\mathrm{S}$. cumini is rich in anthocyanins, which could contribute to its pharmacological properties. Various extracts from different parts of S. cumini were reported for its antidiabetic, antimicrobial, antibacterial, antivirus, antifungal, antiinflammatory and antidiarrheal activities. In this research, organic solvent extractions are performed on the local S. cumini. The methodologies also include thin layer chromatography and phytochemical screening, in identifying the phytochemicals. In summary, it is expected that alkaloids are the component of the leaves extract.

Keywords: Myrtaceae, Syzygium, phytochemistry. 